\title{
Bat point counts: a novel bat sampling method shines light on flying bat communities
}

\author{
Kevin Felix Arno Darras ${ }^{1}$, Ellena Yusti ${ }^{2}$, Joe Chun-Chia Huang ${ }^{3}$, Delphine-Clara Zemp ${ }^{1}$, \\ Agus Priyono Kartono ${ }^{4}$, and Thomas Cherico Wanger ${ }^{5}$ \\ ${ }^{1}$ University of Göttingen \\ ${ }^{2}$ Jambi University \\ ${ }^{3}$ Southeast Asian Bat Conservation and Research Unit \\ ${ }^{4}$ IPB University \\ ${ }^{5}$ Westlake University
}

August 31, 2021

\begin{abstract}
Emerging technologies based on the detection of electro-magnetic energy offer promising opportunities for sampling biodiversity. We exploit their potential bye showing here how they can be used in bat point counts - a novel method to sample flying bats - to overcome shortcomings of traditional sampling methods, and to maximise sampling coverage and taxonomic resolution of this elusive taxon with minimal sampling bias. We conducted bat point counts with a sampling rig combining a thermal scope to detect bats, an ultrasound recorder to obtain echolocation calls, and a near-infrared camera to capture bat morphology. We identified bats with the first dedicated identification key combining acoustic and morphological features, and compared bat point counts to the standard bat sampling methods of mist netting and automated ultrasound recording in three oil palm plantation sites in Indonesia, over nine survey nights. Based on rarefaction and extrapolation sampling curves, we show that bat point counts were the most time-efficient and effective method for sampling the oil palm species pool. Point counts sampled species that tend to avoid nets and those that are not echolocating, and thus cannot be detected acoustically. We identified some bat sonotypes with near-infrared imagery, and bat point counts revealed strong sampling biases in previous studies using capture-based methods, suggesting similar biases in other regions might exist. While capture-based methods allow to identify bats with absolute and internal morphometry, and unattended ultrasound recorders can effectively sample echolocating bats, bat point counts are a promising, and potentially competitive new tool for sampling all flying bats without bias and observing their behavior in the wild.
\end{abstract}

Kevin Felix Arno Darras ${ }^{1,2}$, Ellena Yusti ${ }^{3 *}$, Joe Chun-Chia Huang ${ }^{4 *}$, Delphine-Clara Zemp ${ }^{5,6}$, Agus Priyono Kartono $^{7}$, Thomas Cherico Wanger ${ }^{2,8,9}$

1: Agroecology, Department of Crop Sciences, University of Göttingen, Göttingen, Niedersachsen, Germany 2: Sustainable Agriculture \& Technology Lab, School of Engineering, Westlake University, Hangzhou, China 3: EFForTS, University of Jambi, Jambi, Indonesia

4: Southeast Asian Bat Conservation and Research Unit, 70415 Lubbock, USA

5: Biodiversity, Macroecology and Biogeography, University of Göttingen, Göttingen, Niedersachsen, Germany

6: Laboratory of Conservation Biology, Institute of Biology, University of Neuchâtel, Switzerland 
7: Department of Forest Resources Conservation and Ecotourism, Faculty of Forestry, IPB University, Jl. Ulin No 1 Lingkar Akademik Kampus IPB Darmaga, Bogor, Indonesia

8: Key Laboratory of Coastal Environment and Resources of Zhejiang Province, Westlake University, China

9: GlobalAgroforestryNetwork.org, China

*: these authors contributed equally to this work

Corresponding authors: Kevin Felix Arno Darras (kdarras@westlake.edu.cn) \& Thomas Cherico Wanger (tomcwanger@westlake.edu.cn), 18 Shilongshan Street, Sustainability Agriculture \& Technology Lab, 18 Shilongshan Street, Xihu district, 310024 Hangzhou, China

Running title: Bat point counts shine light on wild bats

Word count: summary: 280; main text: 4471, acknowledgements: 67, references: 1689, tables and figure legends: 696

\section{Summary}

Emerging technologies based on the detection of electro-magnetic energy offer promising opportunities for sampling biodiversity. We exploit their potential bye showing here how they can be used in bat point counts - a novel method to sample flying bats - to overcome shortcomings of traditional sampling methods, and to maximise sampling coverage and taxonomic resolution of this elusive taxon with minimal sampling bias. We conducted bat point counts with a sampling rig combining a thermal scope to detect bats, an ultrasound recorder to obtain echolocation calls, and a near-infrared camera to capture bat morphology. We identified bats with the first dedicated identification key combining acoustic and morphological features, and compared bat point counts to the standard bat sampling methods of mist netting and automated ultrasound recording in three oil palm plantation sites in Indonesia, over nine survey nights. Based on rarefaction and extrapolation sampling curves, we show that bat point counts were the most time-efficient and effective method for sampling the oil palm species pool. Point counts sampled species that tend to avoid nets and those that are not echolocating, and thus cannot be detected acoustically. We identified some bat sonotypes with near-infrared imagery, and bat point counts revealed strong sampling biases in previous studies using capture-based methods, suggesting similar biases in other regions might exist. While capture-based methods allow to identify bats with absolute and internal morphometry, and unattended ultrasound recorders can effectively sample echolocating bats, bat point counts are a promising, and potentially competitive new tool for sampling all flying bats without bias and observing their behavior in the wild.

Short summary : Bat point counts are a modern, novel sampling method combining thermal, ultrasonic, and near-infrared sensors. It rivals and potentially out-performs mist-netting and passive acoustic monitoring. We showcase the unique advantages of the method offers and how it shines a new light on all types of flying bats.

Keywords : biodiversity sampling, Chiroptera, near-infrared, point count, thermal, ultrasound

\section{Introduction}

Biodiversity sampling is biased towards species that are easily and directly detectable with our human senses (Moussy et al., 2021). Even though remote visible light imagery has been used for decades (Blackwell et al., 2006; Cutler \& Swann, 1999), newer technologies based on the detection of the broader electromagnetic energy spectrum are becoming more accessible and further facilitate detecting and identifying animals passively and remotely (Turner et al., 2003; Vance et al., 2016). The applications in ecology and biodiversity conservation have great potential for scientists and conservationists (Pimm et al., 2015), especially when 
sampling elusive animals. Here, we focus on the detection of bats (Chiroptera), a taxon that is notoriously difficult to sample because they are nocturnal, fast, and silent fliers. This partly explains the relative lack of knowledge about bats, although they are the second most diverse order of mammals, provide important, wide-ranging ecosystem services, and experience acute threats (Frick et al., 2020; Kunz et al., 2011).

Bats are typically studied by capture using traps or by roost surveys. Mist netting and harp-trapping are the most common sampling methods for bats outside of their roosts. They are valuable for measuring the bats' morphology precisely, taking physical samples (blood, tissue, parasites), assessing their physiological status, and estimating bat abundance directly. However, they are logistically challenging and have biases: species flying above nets (e.g., large fruit bats) are rarely caught, nets are avoided by some echolocating bats (e.g. "whispering bats"), and other bats can learn to avoid them, requiring daily net moving (Marques et al., 2013). Harp traps are more effective for some species, but they have variable performance (Berry et al., 2004) and may be more useful in South-east Asia (Furey et al., 2010). Furthermore, permits are often needed for catching bats, their handling comes with potential zoonotic risks (Wong et al., 2007), the animals become stressed and more vulnerable to predation (Rocha-Mendes \& Bianconi, 2009), and can even succumb to this invasive sampling method.

Passive acoustic monitoring is also commonly used for sampling bats, since most bats vocalise in the ultrasonic range for navigation with so-called echolocation calls. Passive ultrasound recording relies on automated devices to record echolocation calls made by bats. Single, cheap devices can sample large spaces and be programmed to record for long durations. However, the vast majority of Pteropodidae, occurring in the Paleotropics and Oceania, do not echolocate (except genusRousettus), which explains why capture-based methods are essential there. Still, little is known about bat acoustics in the tropics, and acoustic methods need to be adopted more widely, especially in the Paleotropics (Kingston, 2010). Also, bats do not necessarily have species-specific echolocation calls, and calls are variable (Obrist, 1995). As a result, many species cannot be distinguished on the basis of ultrasound alone and are grouped within "sonotypes" (Walters et al., 2013). Finally, very high frequency bat calls usually attenuate quickly in air and are seldom picked up by microphones that have declining sensitivity with frequency. Some bats also produce narrow ultrasound beams which are less likely to hit a microphone (Brinkløv et al., 2011). Finally, sound detection spaces are species-specific and seldom accounted for (K. Darras et al., 2016). Thus, acoustic detection and identification of bats is challenging, and density estimation is nearly impossible - especially across species.

Mist-netting and passive acoustic monitoring are now established, standardized sampling methods for bat biodiversity surveys (Flaquer et al., 2007). It is often advised to combine both methods to reduce the overall sampling bias (Kuenzi \& Morrison, 1998), especially where Pteropodidae occur. However, recently, a proofof-concept has been proposed for technologically enhanced point counts to sample flying bats at night (K. Darras et al., 2021). These enhanced bat point counts are an active (i.e., requiring a human operator) sampling method to detect and identify all flying bats within a sampling area at night, combining thermal sensing to detect flying bats, ultrasound sampling to record their echolocation calls, and near-infrared imagery to capture their morphology. Thermal and near-infrared imagery have been used before to count bat colonies directly in caves (Betke et al., 2008; Sabol \& Hudson, 1995), and thermal imaging has also been combined with ultrasound recording to detect bats with drones (Fu et al., 2018) and at wind farms (Correia et al., 2013). Near-infrared imaging can also detect pollinating bats (Frick et al., 2009). However, these studies surveyed sites with a great density of inactive bats, or focused on specific sites where a particular interaction occurs. Near-infrared imaging has not been used yet for identifying flying bats passively; it remains to be seen whether entire bat communities can be sampled with this method and how it compares to established methods.

Here, we showcase bat point counts and demonstrate how they can be used for ecological studies. We compare them against mist-netting and ultrasound recording in an agricultural system in the Paleotropics, where both insectivorous, echolocating bats and frugivorous, non-echolocating bats are common. We measure the detection spaces of all three sampling methods, present a novel, morphological-acoustic bat identification key tailored to our study system to make use of the acoustic and photographic data, investigate how accurately 
and efficiently the species pools are sampled by each method, and compare diversity patterns using rarefaction and extrapolation sampling curves. We discuss practical considerations, and we give an outlook as to the new possibilities offered by bat point counts for the study of bats.

\section{Materials and methods}

\section{Study site and design}

We surveyed bats in three different sites in a closed-canopy oil palm plantation using bat point counts, mist nets, and automated ultrasound recorders. Our sampling sites are inside the Humusindo Makmur Sejati $\left(01.95^{\circ} \mathrm{S}\right.$ and $103.25^{\circ} \mathrm{E}, 47 \pm 11 \mathrm{~m}$ a.s.l.) company estate, near Bungku village in the lowlands of Jambi province, Sumatra, Indonesia. We set the center of each site within $10 \mathrm{~m}$ of a stream (2-4 m wide) and an unpaved road (4-5 m wide) in order to maximise potential species detections, as it is widely known that bats use trails and streams for commuting and hunting (Voigt \& Kingston, 2016). The sites were bordering the same river and separated by at least $600 \mathrm{~m}$ to allow independent captures. We sampled all three sites simultaneously with rotating methods on three consecutive nights with one field team, and we repeated this twice, obtaining three sampling nights for each method and site in total (Fig 1). The surveys occurred during nine nights from 21 to 31 May 2019. Due to our selection of sites with identical surrounding habitats, the temporally rotating design of the methods, the simultaneous comparison of methods in equivalent sites, and the short sampling period, any effects of weather conditions, moon phase, and fluctuating food resource availability was minimized and should not bias our results.

\section{Bat point counts}

We conducted bat point counts for one hour per night in each site. We used a sampling rig with sensors for ultrasound, thermal, and infrared waves; we provide full technical details of the rig and the observation workflow in (K. Darras et al., 2021). Each point count scanned a $120^{\circ}$ field of view, directed either towards the road, river, or oil palm. We determined the detection area of the thermal scope and the full-spectrum microphone - fitted with a horn to amplify sounds from the front - with a chirp emitter at $40 \mathrm{kHz}$ (K. Darras et al., 2021). The first three point counts took place in the first hour after the survey started, and the next three point counts happened in the second hour. Between the two hours, the bat point counts team assisted bat extraction at the mist netting site that was permanently attended by a third person. Thus, it was not possible to sample bats with point counts for the same duration as with the other methods.

\section{Mist netting}

We mist-netted bats for 4 hours per night for a total of 576 net-hours $(\mathrm{mh})$ in each site. Mist netting was our reference trapping method for sampling bats: we did not use harp traps as they were ineffective in previous assessments in oil palm plantations in our region (Darras, unpublished data). We opened four $3.2 \mathrm{~m}$ high $\mathrm{x} 12 \mathrm{~m}$ long nets 1 to $1.5 \mathrm{~m}$ above the ground for four hours starting at sunset (Ultra Thin Series M Mist Net, $20 \mathrm{~mm}$ mesh, Ecotone). Nets were installed in presumed flight ways, delimited a quadrilateral, and their position relative to the river, oil palm, or road was approximately the same in all plots for each survey set. Most of the below-canopy flying space was covered with our nets. Mist nets were checked every 15 minutes from sunset to two hours afterwards, then every 30 minutes until four hours after sunset. Captured bats were kept in tissue pouches until the nets were closed. Bat morphology was measured to identify bats according to (Huang et al., 2014) directly in the field. There were no particular regulations or ethical guidelines for research on live bats in Indonesia at the time of the study, but we wore protective equipment (masks and gloves) to handle them. 


\section{Ultrasound recordings}

We made continuous ultrasoundscape recordings (i.e., without triggers) with sound recorders for 4 hours per night in each site. One recorder (SM2Bat+, Wildlife Acoustics) were set up with one microphone (Parus open-source model, (K. Darras et al., 2018)) parallel to the ground, sampling at $384 \mathrm{kHz}$ at $2 \mathrm{~m}$ height, starting at sunset and lasting four hours in each site. We measured the ultrasound detection space covered by the recorders (K. Darras et al., 2016): similarly to bat point counts, we pointed an ultrasound calibrator (Wildlife Acoustics) to the recorder, and recorded its $40 \mathrm{kHz}$ chirps emitted from $2 \mathrm{~m}$ height at distances of $4,8,16$, and $32 \mathrm{~m}$, in three directions (to the river, the road, and the oil palm plantation) to derive the site's sound transmission profiles (Fig S3).

\section{Data analysis}

\section{Species identification}

Ultrasound recordings from bat point counts and automated ultrasound recorders were uploaded on the open-source platform BioSounds (K. Darras et al., 2020) to annotate the spectrograms with identitfied bat detections; we included both acoustic as well as thermal-only detections (detections without ultrasound that were vocally mentioned by the observer) (K. Darras et al., 2021). All bat calls were identified using our reference collection of bat calls obtained from captured bats (Chiroptera reference collection in BioSounds (K. Darras et al., 2020)) and literature data (Hughes et al., 2011; Kingston, 2013; Zhu et al., 2012). We distinguished broadband frequency-modulated (BFM), constant-frequency $(\mathrm{CF})$, and frequency-modulated, quasi-constant frequency (FM-QCF) calls. We measured calls for each bat call type within each recording, but only if the bat pass was recorded clearly (to avoid biased call parameters from distant calls), using the three strongest, not saturated calls: We measured peak frequency (Fmax, frequency with maximum energy), start frequency, end frequency, call duration, and inter-call interval (from the start of one call to the onset of the next). Frequency-modulated quasi-constant frequency (FM-QCF) calls were split in three sonotypes based on their end frequency: around $33 \mathrm{kHz}$, between 38 and $42 \mathrm{kHz}$, and around $48 \mathrm{kHz}$.

We matched ultrasound recordings and near-infrared photographs from bat point counts to their respective detections using a conservative workflow that discarded uncertain matches (K. Darras et al., 2021). We used data from one additional, incomplete survey night during which our infrared lamp power supply failed to aid with the taxonomic identification. Bat species identification usually relies on direct, external and internal body part measurements and categorical features of caught specimens. However, absolute measurements from pictures are inaccurate due to our large depth of field of approximately four meters: a $10 \mathrm{~cm}$ bat at a distance of $8 \mathrm{~m}$ would appear as large as a $15 \mathrm{~cm}$ bat at $12 \mathrm{~m}$. Thus, we rely on categorical features as well as relative measurements of external, readily recognisable body parts - as they do not depend on the bats' distance - for identifying bat point count detections. We used pixel-measuring software tools on photos where the measured body parts were parallel to the camera focus plane to avoid underestimates. We only used near-infrared images to identify thermal-only detections. We confirmed or determined the identity of bat sonotypes in bulk by using clear near-infrared pictures of selected detections. We devised a new identification key for South-East Asian bats found in oil palm based on (Huang et al., 2014) to determine bat identity from near-infrared pictures and ultrasound calls (Box 1).

\section{Rarefaction and extrapolation sampling curves}

We compared the species richness sampling effectiveness of bat point counts against mist netting and automated ultrasonic recording by comparing the size of the species pools sampled by each method using rarefaction and extrapolation sampling curves (Chao et al., 2014). We pooled all three sampling sites to represent our oil palm plantation's bat community. We calculated a conservative estimate of each species' abundance in sound recordings by usingthe maximum number of simultaneously recorded bats per night. We computed taxon presence/absence at each sampling hour and method as well as abundance matrices for each method, by summing the species abundances over the three sites. We only used the taxonomic 
identities yielded by each sampling method, independently of the insights gained from the other methods. We generated raw incidence as well as abundance-based rarefaction and extrapolation sampling curves and compared the number of species at a $95 \%$ sampling coverage for a robust estimation of diversity (Hsieh et al., 2016). We assessed the statistical significance of differences in species richness between sampling methods with $83 \%$ confidence intervals (Krzywinski \& Altman, 2013).

\section{Acoustic and thermal detection ranges}

Thermal detection ranges of bat point counts were obtained for each direction by measuring the maximal distance at which the hand of a field assistant was detectable in the thermal scope. Acoustic detection ranges for point counts (with ultrasonic horn) and automated ultrasound recordings (without horn) were obtained for each direction from the intersection of the chirp emitter's sound level curve against distance with the ambient sound level (K. Darras et al., 2016). Sampling spaces of mist nets are not determinable per se, but we assumed that they cover at least the inner area delimited by their border.

\section{Results}

\section{Detected species}

We found 100 thermal detections of seven taxa in point counts, 2009 detections of six taxa in automated ultrasonic recordings, and captured 83 bats from seven species in mist nets (Fig. 3). We excluded eight point count detections where neither ultrasound nor near-infrared pictures were recorded. We found one BFM, three CF, and three FM-QCF sonotypes (Table S1, Figure S1). We identified the FM sonotype to genus in automated ultrasound recordings, but found its putative identity from mist-netting data (Kerivoula pellucida ). We identified all CF sonotypes to species (Hipposideros kunzi, H. orbiculus, Rhinolophus sedulus ), and none was found using mist nets. All FM-QCF sonotypes were found using bat point counts and automated ultrasound recordings. One FM-QCF was identified to species using acoustic data (Pipistrellus stenopterus, (Kingston, 2013)) and was not found in mist nets. Using relative measurements from near-infrared imagery, one FM-QCF sonotype consisting of two candidate species was resolved to species-level in point counts (Scotophilus kuhlii ); it was the only species detected by all methods. The third FM-QCF sonotype was a complex of six candidate species and was reduced to three candidate species using near-infrared imagery. It was putatively identified with mist-netting (undescribed Myotis sp.1sensu (Huang et al., 2014)). One pteropodid genus (Cynopterus sp.) was detected in bat point counts and resolved to three distinct species in the mist-netting dataset (Cynopterus sphinx, C. brachyotis, C. minutus). Mist nets detected one pteropodid species from another genus (Macroglossus minimus) and conversely, aEonycteris/Rousettus genera complex was detected in bat point counts.

\section{Rarefaction and extrapolation sampling curves}

At $95 \%$ sampling coverage, with incidence-based data, bat point counts detected a higher mean projected species richness, earlier than other methods; with abundance-based data, bat point counts reached a higher mean projected species richness, but at higher numbers of individuals (Fig. 2). At low numbers of sampling hours ([?] 2.5) and of sampled individuals ([?] 20), bat point counts and automated recordings allowed to detect significantly more species than mist-netting. The abundance-based extrapolation curves saturated more quickly for ultrasound recording and mist netting than for bat point counts, indicating that bat point counts had a higher probability to detect new species with increasing numbers of individuals. We provide an in-depth analysis of rarefaction-extrapolation sampling curves (Text S3, Fig S2). 


\section{Acoustic and thermal detection spaces}

Bat point counts swept a large thermal detection area that encompassed a larger area than our mist nets, and their ultrasound detection spaces were larger and more narrow than those of the automated ultrasound recorders (Fig. 1). Ultrasound detection ranges of bat point counts (where the microphone was fitted with a horn) were almost three times larger than the unattended ultrasound recorders' ranges (without horn) in the direction the microphone was pointing to (bat point counts: $450 \mathrm{~m}$; automated ultrasound recorders: $164 \mathrm{~m}$ ), and to some degree also to the side (Figure S3). The thermal scope had a range of $48 \mathrm{~m}$ on average, with a minimum of $19 \mathrm{~m}$ to a maximum of $84 \mathrm{~m}$; its range was usually limited by obstacles such as oil palms or terrain irregularities. The mist nets approximately delimited an area of $150 \mathrm{~m}^{2}$ when a quadrilateral was drawn across their outer corners.

\section{Discussion}

\section{Bat point counts versus traditional sampling methods}

For sufficient sampling effort (i.e. $>2.5$ sampling hours or $>20$ individuals), the bat point counts had a higher probability to detect new species than traditional methods, potentially better representing the total species pool. In our study, mist-netting did not perform well due to the hyper-dominance of Cynopterus brachyotis in mist net captures, and passive acoustic monitoring cannot detect the five non-echolocating bat species. Logistical constraints did not allow for longer sampling durations in bat point counts to detect more species and increase confidence of our estimates, and additional personnel could have introduced a sampling bias. Nonetheless, in one quarter of the sampling duration of the other sampling methods, bat point counts were tied in the first place with mist-netting for raw taxa counts. Given that the bat point counts sample was almost complete in the shortest time and allowed to detect relatively more species than using the other methods, the new bat point count method can be considered the most effective and time-efficient. It follows that bat point counts could be especially attractive for rapid assessments or for researchers with time constraints in the field.

Theoretically, passive collection of complementary acoustic and visual data enables bat point counts to detect echolocating and non-echolocating bat types without bias. Correspondingly, point counts could be particularly useful as a single sampling method in the Paleotropics and Oceania, where both types coexist. As a consequence, in our study, they reached the highest species richness at equal sampling coverage with the traditional sampling methods. Admittedly, if the aim was to detect a maximum number of species, combining mist nets with passive recording could yield better results than bat point counts. However, the logistical effort and expertise requirements should not be underestimated, and bat incidences from studies based on these different methods are not directly comparable. As a result, bat point counts are currently the only way to obtain unbiased prevalences of echolocating and non-echolocating bats, foregoing potential methodological and taxonomic incompatibilities between sampling methods.

By design, bat point counts should have a smaller taxonomic sampling bias compared to established sampling methods. All bats must be detectable thermally as they are metabolically active, hence warmer than the surrounding environment. Their detectability depends mainly on their size and distance to the thermal scope. The larger bats we caught were approximately $10 \mathrm{~cm}$ large (from head to tail - roughly the palm of the hand used to determine detection distances), and could be detected - albeit presumably not identified at up to $80 \mathrm{~m}$. Geometrically, $4 \mathrm{~cm}$ large bats would thus have a detection area of $32 \mathrm{~m}$ radius. In contrast, bat diversity studies that are based on trapping and acoustics rarely account for the detectability of different species when comparing community across space. Ultrasound detection ranges are highly variable and species-specific as they depend strongly on the frequency, sound level, and directivity of the calls (K. Darras et al., 2016). Also mist-netting species abundances depend on their exact setup, which cannot systematically be reproduced across studies, and given the taxonomic sampling biases mentioned earlier, they are unlikely to be comparable across species. It follows that with our approach, specific thermal detection ranges are 
relatively easily measured and likely have less biased detectability between species, so that the corresponding density estimates can be computed more accurately and compared across species.

Bat point counts revealed that in our region, there is a strong sampling bias against insectivorous bats. Acoustic monitoring alone cannot reveal the magnitude of that bias, and although mist netting potentially could, four echolocating species were not caught with our mist nets at all - even though Hipposideridae and Rhinolophidae were caught in other studies (Fukuda et al., 2009; Huang et al., 2014). Previous studies from oil palm plantations in Southeast Asia used only mist nets so far, and perhaps as a consequence, it is recurrently stated that they are dominated by frugivorous bats - especially Cynopterus brachyotis(Azhar et al., 2015; Fukuda et al., 2009; Mohd-Azlan, 2019; Syafiq et al., 2016). In contrast, in bat point counts, only seven out of 100 detections came from Pteropodidae, and this ratio might even be lower when considering their higher detectability due to their larger size. These results are consistent with the fact that oil palm monocultures do not provide food for Pteropodidae; they usually fly through to forage on fig trees on river banks (pers. obs. KD, EY). Thus, it appears that much of the bat assemblage is ignored when using only mist nets, underlining their strong taxonomic bias in our system (Huang et al., 2019), and suggesting similar biases in other tropical studies might exist. As a consequence, the contribution of bat communities to regulating insect populations in oil palm may also have been underestimated.

The three methods we tested have different practical requirements (Table 1). Taxonomic expertise is needed for all methods, but in the case of point counts and automated ultrasound recordings, it can be delayed or out-sourced: species identification can be done by experts using computers, anytime. Data processing is time-effective for mist-netting as data can typically be entered after the survey. However, sound recordings must usually be retrieved, uploaded and annotated recordings, and for bat point counts, photographs must additionally be processed analogously. In our study with our iteratively developed workflow, we estimate a post-survey workload that is approximately equal to the duration of the acoustic recordings to annotate and identify bat passes. For bat points counts, another two to five minutes processing time per detection can be added to obtain detection statistics and identification features, however, the acoustic processing can be considerably shortened by focusing on thermal detections, which made up only $6 \%$ of the total recording time. Regarding initial costs, mist netting requires considerable training, and point counts currently require high expertise and expenses for the assembly of the sampling rig. In our study, high-end hardware was already available, but we estimated lower costs for all methods with alternative hardware at equal performance (Table 1): much cheaper, equivalent sound recorders can be obtained (Hill et al., 2019), and currently, a complete rig can be built for approximately 2200 EUR. Although the initial hardware costs of bat point counts can be prohibitive for less well-funded research projects, we strive to develop the bat point counts rig further (K. Darras et al., 2021) to lower the costs and increase availability. In comparison to mist-netting, sound recorder installation and bat point counts can be carried out more easily by trained personnel, even alone, if safety at night is no concern.

\section{Application challenges and research opportunities}

Point counts potentially cover large sampling areas, but they depend on the surveyed site, as clear lines of sight are required. In our study, the sparse understory allowed us to detect bats at relatively long ranges (48 $\mathrm{m}$ ) that were only limited by larger obstacles such as palms or uneven terrain. We can predict that in even, open terrain without trees, the detection spaces would be even greater (approximately $80 \mathrm{~m}$ - the maximum range we measured). However, in previous trials with a prototype sampling rig in a forest with dense understory vegetation, the detection range was more limited (approximately $18 \mathrm{~m}$, pers. obs. EY). Hence, we suggest choosing good vantage points or clearing lower, nearby vegetation that considerably obstructs the field of view. More importantly, irrespective of the variability of detection ranges, detection ranges are ultimately measurable so that detectability variations can be accounted for to obtain rough density estimates, an approach that is still biased for mist netting studies, and rare for acoustic studies. Theoretically, bat point counts could even be used to derive more reliable density estimates from distance sampling approaches: using the first detection of each species (a standard approach for avoiding double-counting) and its angular 
size, detection distances could be estimated. Finally, to solve the issue that only a part of the surroundings are thermally sampled at any point in time, thermal scopes with higher resolution and larger field of view could be used to cover a larger detection area.

Bat point counts are a fundamentally different method that requires human presence but does not capture any live specimens. Instead, users must become proficient with the handling of acoustic and photographic data. Our technical information and workflows (K. Darras et al., 2021) as well as our ecoacoustic software tools (K. Darras et al., 2020) and our identification key presented here facilitate that process. However, different sampling regions - and to some degree, habitats - currently require dedicated identification keys. So far, identification keys are based on absolute external, and sometimes internal morphological measurements and features, and none use acoustic data to out knowledge. Researchers often cannot make complementary ultrasound recordings when capturing bats, and flying-tent or hand-release recordings can yield calls that are atypical of free-flying bats (Dietz \& Kiefer, 2015). However, we showed that it is precisely the complementarity of acoustic and photographic data that improves taxonomic identification, and we are the first to develop such an identification key that combines acoustic and morphological features. We suggest that this becomes a research priority.

Bat point counts will resolve more species and individuals as the technology matures and yields better nearinfrared imagery (K. Darras et al., 2021). One of our sonotypes remains unidentified, but it is likely that we will be able to discriminate between its candidate species. Some detections included in that sonotype likely belonged toMiniopterus sp., but this was based on the personal experience of co-author JCH with that genus' phenotype, which is challenging to reproduce. At the moment, frugivores are lumped into theCynopterus genus because species identification requires internal and absolute body metrics. Still, it is possible to distinguish them from genera which have distinct head shapes and body sizes. Better near-infrared imagery will increase the proportion of usable pictures, and reveal the wing bones and face more clearly. This would further improve the shape of the species accumulation curves and increase their confidence. We also photographed detailed morphological features that could aid in discriminating between individuals: we sexed a male Cynopterus by its visible penis, and indentified it as an individual with a hole in its wing (Text S2). These individual signatures would yield more realistic abundance estimates and provide information for the conservation of wild populations.

Morphological and acoustic data from point counts could be invaluable for resolving species complexes (consisting of several candidate identifications). Analogously to our present attempts, we are hopeful that sonotypes can be resolved with more taxonomic depth, such as for "whispering" bat species (e.g., Phyllostomidae) (Yoh et al., 2020). The recordings obtained from bat point counts, using an ultrasonic horn, were also more amenable to call libraries: 1) their signal-to-noise ratio is consistently higher, as the horn amplifies the sounds from an actively tracked bat; 2) call durations are more accurately measurable, as echoes from the surroundings are shielded by the horn; 3) calls are representative of free-flying bats, unlike calls from handheld bats, bats flying in tents, and likely also calls from distraught, released bats. It follows that bat point counts can yield reference data to identify unresolved sonotypes inside unattended recordings, even a posteriori. Conversely, acoustic data can resolve "cryptic" species complexes that are morphologically almost indistinguishable: although we found only one member of the Hipposideros bicolor complex,Hipposideros $k u n z i$ was readily identified using its calls' maximum energy frequency (Murray et al., 2018). Interestingly, mist-net captures could be used to generate reference near-infrared reference photographs for facilitating identification from pictures of free-flying bats, using coloration differences that we were not able to use here. Potentially, the flight pattern observed in the thermal scope can also be diagnostic (K. F. A. Darras, 2020), but their usefulness must be evaluated more throughly.

The combination of direct visual observation with ultrasonic recording allows to study bat behavior (Text S2). Interactions between individuals (within and between species) can be observed - we saw several encounters between bats. In some cases, the bats would fly together, and in other cases, they would avoid each other. Possibly, the function of social calls could be elucidated and linked to competition for critical resources (Corcoran \& Conner, 2014) or partners (Voigt et al., 2008), or calls from individual bats with different ages, 
sexes, and group memberships (Kao et al., 2020; Pfalzer \& Kusch, 2003; Siemers et al., 2005). Second, flight maneuvers such as diving can be seen (Text S2), giving insights about hunting behavior: we observed several dives and potentially a catch on the wing. Also, the head position was variable, appearing to indicate the echolocating direction for scanning prey and obstacles, and helping their identification. Finally, the exact coupling of photographic and audio data reveals what calls are emitted in which situation or environment for instance during a diving maneuver (Text S3) - and when exactly bats emit feeding buzzes and social calls (Middleton et al., 2014). Previously, such observations were only possible in carefully controlled artificial environments such as tunnels with extensive setups (Clark, 2021).

\section{Conclusion}

Bat point counts are a new tool for ecologists and a promising avenue for sampling flying bat communities comprehensively and efficiently. Technological advances will lower the cost and increase the practicability and efficacy of bat point counts in the near future (K. Darras et al., 2021). The method needs to be evaluated further in different environments with more speciose bat assemblages. Still, mist-netting is obviously needed for capturing and measuring undescribed species, for taking samples, and for assessing the physiology; it currently delivers the highest, usually species-level identification accuracy. Also automated ultrasound recordings are an effective, standardised, and practical way of sampling echolocating bats. Yet, bat point counts are unique and they could potentially be used in conjunction with bird point counts to comprehensively sample all flying vertebrates. The potential of newer technologies should be embraced to advance chiropterology and advance fundamental and applied research questions in ecology and conservation. Bat point counts, as a direct observation method that makes bats audible and visible, shines a new light on flying bat communities and their behavior, and will potentially lead to radically new insights.

\section{Author contributions}

The authors declare to have no interest conflicts. KD designed the study, analysed the data, ad wrote the manuscript. EY conducted the field studies. EY, JCH and APK analysed the data. All authors contributed to the manuscript writing.

\section{Acknowledgements}

We thank Ilham and Erick Mandelson for the unwavering nightly field work, and Ingo Grass for critically constructive comments on the manuscript draft. Arne Wenzel and Xueqing He provided valuable comments. This study was funded by the Deutsche Forschungsgemeinschaft (DFG, German Research Foundation)project number 192626868-SFB 990 in the framework of the collaborative German-Indonesian research project CRC990. We declare that the authors have no conflicts of interest.

\section{Data accessibility}

The data required for reproducing our results will be archived in the supplementary materials. The technical details for assembling a bat point count rig, as well as the working protocol, are published elsewhere (K. Darras et al., 2021). The annotated ultrasound recordings are available publicly on BioSounds (K. Darras et al., 2020), and all infrared photographs are available on OSF (K. F. A. Darras, 2020). 


\section{Literature cited}

Azhar, B., Puan, C. L., Aziz, N., Sainuddin, M., Adila, N., Samsuddin, S., Asmah, S., Syafiq, M., Razak, S. A., Hafizuddin, A., Hawa, A., \& Jamian, S. (2015). Effects of in situ habitat quality and landscape characteristics in the oil palm agricultural matrix on tropical understory birds, fruit bats and butterflies. Biodiversity and Conservation,24(12), 3125-3144. https://doi.org/10.1007/s10531-015-1005-6

Berry, N., O'Connor, W., Holderied, M. W., \& Jones, G. (2004, September). Detection and avoidance of harp traps by echolocating bats [Text]. https://doi.org/info:doi/10.3161/1508110042955478

Betke, M., Hirsh, D. E., Makris, N. C., McCracken, G. F., Procopio, M., Hristov, N. I., Tang, S., Bagchi, A., Reichard, J. D., Horn, J. W., \& others. (2008). Thermal imaging reveals significantly smaller Brazilian free-tailed bat colonies than previously estimated. Journal of Mammalogy, 89(1), 18-24.

Blackwell, B. F., Seamans, T. W., Washburn, B. E., \& Cepek, J. D. (2006). Use of Infrared Technology in Wildlife Surveys. Proceedings of the Vertebrate Pest Conference, 22(22). https://doi.org/10.5070/V422110116

Brinklov, S., Jakobsen, L., Ratcliffe, J. M., Kalko, E. K. V., \& Surlykke, A. (2011). Echolocation call intensity and directionality in flying short-tailed fruit bats, Carollia perspicillata (Phyllostomidae). The Journal of the Acoustical Society of America, 129(1), 427-435. https://doi.org/10.1121/1.3519396

Chao, A., Gotelli, N. J., Hsieh, T. C., Sander, E. L., Ma, K. H., Colwell, R. K., \& Ellison, A. M. (2014). Rarefaction and extrapolation with Hill numbers: A framework for sampling and estimation in species diversity studies.Ecological Monographs, 84(1), 45-67. https://doi.org/10.1890/13-0133.1

Clark, C. A. (2021, March 21). Researchers Learning From The Brainy Bats Of Borneo. https://ladailypost.com/researchers-learning-from-the-brainy-bats-of-borneo/

Corcoran, A. J., \& Conner, W. E. (2014). Bats jamming bats: Food competition through sonar interference. Science, 346(6210), 745-747. https://doi.org/10.1126/science.1259512

Correia, R., Faneca, C., Vieira, J. M. N., Bastos, C., Mascarenhas, M., Costa, H., Bernardino, J., Fonseca, C., \& Pereira, M. J. R. (2013). Bat Monitoring System for Wind Farms. IFAC Proceedings Volumes, 46(28), 110-115. https://doi.org/10.3182/20130925-3-CZ-3023.00024

Cutler, T. L., \& Swann, D. E. (1999). Using Remote Photography in Wildlife Ecology: A Review. Wildlife Society Bulletin (1973-2006), 27(3), 571-581.

Darras, K. F. A. (2020). Bat point counts. Open Science Framework. https://doi.org/10.17605/OSF.IO/RQYH8

Darras, K., Kolbrek, B., Knorr, A., \& Meyer, V. (2018). Assembling cheap, highperformance microphones for recording terrestrial wildlife: The Sonitor system.F1000Research, 7, 1984. https://doi.org/10.12688/f1000research.17511.1

Darras, K., Perez, N., -, M., \& Hanf-Dressler, T. (2020). BioSounds: An open-source, online platform for ecoacoustics. F1000Research, 9, 1224. https://doi.org/10.12688/f1000research.26369.1

Darras, K., Putz, P., Fahrurrozi, Rembold, K., \& Tscharntke, T. (2016). Measuring sound detection spaces for acoustic animal sampling and monitoring.Biological Conservation, 201, 29-37. https://doi.org/10.1016/j.biocon.2016.06.021

Darras, K., Yusti, E., Knorr, A., Huang, J. C.-C., Kartono, A. P., \& . I. (2021). Sampling flying bats with thermal and near-infrared imaging and ultrasound recording: Hardware and workflow for bat point counts.F1000Research, 10, 189. https://doi.org/10.12688/f1000research.51195.1

Dietz, C., \& Kiefer, A. (2015). Bats of Britain and Europe. 
Flaquer, C., Torre, I., \& Arrizabalaga, A. (2007). Comparison of Sampling Methods for Inventory of Bat Communities. Journal of Mammalogy, 88(2), 526-533. https://doi.org/10.1644/06-MAMM-A-135R1.1

Frick, W. F., Heady, P. A., III, \& Hayes, J. P. (2009). Facultative Nectar-Feeding Behavior in a Gleaning Insectivorous Bat (Antrozous pallidus). Journal of Mammalogy, 90(5), 1157-1164. https://doi.org/10.1644/09-MAMM-A-001.1

Frick, W. F., Kingston, T., \& Flanders, J. (2020). A review of the major threats and challenges to global bat conservation. Annals of the New York Academy of Sciences, 1469(1), 5-25. https://doi.org/10.1111/nyas.14045

Fu, Y., Kinniry, M., \& Kloepper, L. N. (2018). The Chirocopter: A UAV for recording sound and video of bats at altitude. Methods in Ecology and Evolution,9(6), 1531-1535. https://doi.org/10.1111/2041-210X.12992

Fukuda, D., Tisen, O. B., Momose, K., \& Sakai, S. (2009). Bat diversity in the vegetation mosaic around a lowland dipterocarp forest of Borneo. Raffles Bulletin of Zoology, 57(1), 213-221.

Furey, N. M., Mackie, I. J., \& Racey, P. A. (2010). Bat diversity in Vietnamese limestone karst areas and the implications of forest degradation.Biodiversity and Conservation, 19(7), 1821-1838. https://doi.org/10.1007/s10531-010-9806-0

Hill, A. P., Prince, P., Snaddon, J. L., Doncaster, C. P., \& Rogers, A. (2019). AudioMoth: A low-cost acoustic device for monitoring biodiversity and the environment. HardwareX, 6, e00073. https://doi.org/10.1016/j.ohx.2019.e00073

Hsieh, T. C., Ma, K. H., \& Chao, A. (2016). iNEXT: An R package for rarefaction and extrapolation of species diversity (Hill numbers). Methods in Ecology and Evolution, 7(12), 1451-1456. https://doi.org/10.1111/2041-210X.12613

Huang, J. C.-C., Jazdzyk, E. L., Nusalawo, M., Maryanto, I., Maharadatunkamsi, Wiantoro, S., \& Kingston, T. (2014). A Recent Bat Survey Reveals Bukit Barisan Selatan Landscape as a Chiropteran Diversity Hotspot in Sumatra.Acta Chiropterologica, 16(2), 413-449. https://doi.org/10.3161/150811014X687369

Huang, J. C.-C., Rustiati, E. L., Nusalawo, M., \& Kingston, T. (2019). Echolocation and roosting ecology determine sensitivity of forest-dependent bats to coffee agriculture. Biotropica, 51(5), 757-768. https://doi.org/10.1111/btp.12694

Hughes, A. C., Satasook, C., Bates, P. J. J., Soisook, P., Sritongchuay, T., Jones, G., \& Bumrungsri, S. (2011). Using echolocation calls to identify Thai bat species: Vespertilionidae, Emballonuridae, Nycteridae and Megadermatidae. Acta Chiropterologica, 13(2), 447-455. https://doi.org/10.3161/150811011X624938

Kao, M.-T., Liu, J.-N., Cheng, H.-C., \& Nakazawa, T. (2020). Social signatures in echolocation calls of a leafroosting bat, Kerivoula furva.Bioacoustics, 29(4), 461-480. https://doi.org/10.1080/09524622.2019.1616617

Kingston, T. (2010). Research priorities for bat conservation in Southeast Asia: A consensus approach. BIODIVERSITY AND CONSERVATION, 19(2, Sp. Iss. SI), 471-484. https://doi.org/10.1007/s10531008-9458-5

Kingston, T. (2013). Response of Bat Diversity to Forest Disturbance in Southeast Asia: Insights from Long-Term Research in Malaysia. In R. A. Adams \& S. C. Pedersen (Eds.), Bat Evolution, Ecology, and Conservation (pp. 169-185). Springer. https://doi.org/10.1007/978-1-4614-7397-8_9

Krzywinski, M., \& Altman, N. (2013). Points of significance: Error bars. Nature Methods, 10(10), 921-922.

Kuenzi, A. J., \& Morrison, M. L. (1998). Detection of Bats by Mist-Nets and Ultrasonic Sensors. Wildlife Society Bulletin (1973-2006), 26(2), 307-311.

Kunz, T. H., de Torrez, E. B., Bauer, D., Lobova, T., \& Fleming, T. H. (2011). Ecosystem services provided 
by bats. Annals of the New York Academy of Sciences, 1223(1), 1-38. https://doi.org/10.1111/j.17496632.2011.06004.x

Marques, J. T., Ramos Pereira, M. J., Marques, T. A., Santos, C. D., Santana, J., Beja, P., \& Palmeirim, J. M. (2013). Optimizing Sampling Design to Deal with Mist-Net Avoidance in Amazonian Birds and Bats. PLoS ONE,8(9). https://doi.org/10.1371/journal.pone.0074505

Middleton, N., Froud, A., \& French, K. (2014). Social Calls of the Bats of Britain and Ireland. Pelagic Publishing Ltd.

Mohd-Azlan, J. (2019). The role of forest fragments in small mammal conservation in an oil palm plantation in northern Sarawak, Borneo. Journal of Oil Palm Research. https://doi.org/10.21894/jopr.2019.0034

Moussy, C., Burfield, I. J., Stephenson, P. J., Newton, A. F. E., Butchart, S. H. M., Sutherland, W. J., Gregory, R. D., McRae, L., Bubb, P., Roesler, I., Ursino, C., Wu, Y., Retief, E. F., Udin, J. S., Urazaliyev, R., Sanchez-Clavijo, L. M., Lartey, E., \& Donald, P. F. (2021). A quantitative global review of species population monitoring. Conservation Biology: The Journal of the Society for Conservation Biology. https://doi.org/10.1111/cobi.13721

Muller, B., Goodman, S. M., \& Peichl, L. (2007). Cone Photoreceptor Diversity in the Retinas of Fruit Bats (Megachiroptera). Brain, Behavior and Evolution,70 (2), 90-104. https://doi.org/10.1159/000102971

Murray, S. W., Khan, F. A. A., Kingston, T., Zubaid, A., \& Campbell, P. (2018). A new species in the Hipposideros bicolor group (Chiroptera: Hipposideridae) from Peninsular Malaysia. Acta Chiropterologica, 20 (1), 1-29. https://doi.org/10.3161/15081109ACC2018.20.1.001

Obrist, M. K. (1995). Flexible bat echolocation: The influence of individual, habitat and conspecifics on sonar signal design. Behavioral Ecology and Sociobiology, 36(3), 207-219. https://doi.org/10.1007/BF00177798

Obrist, M. K., Fenton, M. B., Eger, J. L., \& Schlegel, P. A. (1993). What ears do for bats: A comparative study of pinna sound pressure transformation in chiroptera.Journal of Experimental Biology, 180(1), 119152.

Ollivier, F. J., Samuelson, D. A., Brooks, D. E., Lewis, P. A., Kallberg, M. E., \& Komaromy, A. M. (2004). Comparative morphology of the tapetum lucidum (among selected species). Veterinary Ophthalmology, 7(1), 11-22. https://doi.org/10.1111/j.1463-5224.2004.00318.x

Pfalzer, G., \& Kusch, J. (2003). Structure and variability of bat social calls: Implications for specificity and individual recognition. Journal of Zoology,261(1), 21-33. https://doi.org/10.1017/S0952836903003935

Pimm, S. L., Alibhai, S., Bergl, R., Dehgan, A., Giri, C., Jewell, Z., Joppa, L., Kays, R., \& Loarie, S. (2015). Emerging Technologies to Conserve Biodiversity. Trends in Ecology $\& 3$ Evolution, 30(11), 685-696. https://doi.org/10.1016/j.tree.2015.08.008

Rocha-Mendes, F., \& Bianconi, G. (2009). Opportunistic predatory behavior of margay, Leopardus wiedii (Schinz, 1821), in Brazil. Mammalia, 73, 151-152. https://doi.org/10.1515/MAMM.2009.017

Sabol, B. M., \& Hudson, M. K. (1995). Technique Using Thermal Infrared-Imaging for Estimating Populations of Gray Bats. Journal of Mammalogy,76(4), 1242-1248. https://doi.org/10.2307/1382618

Siemers, B. M., Beedholm, K., Dietz, C., Dietz, I., \& Ivanova, T. (2005). Is species identity, sex, age or individual quality conveyed by echolocation call frequency in European horseshoe bats? Acta Chiropterologica,7(2), 259-274. https://doi.org/10.3161/150811005775162579

Syafiq, M., Nur Atiqah, A. R., Ghazali, A., Asmah, S., Yahya, M. S., Aziz, N., Puan, C. L., \& Azhar, B. (2016). Responses of tropical fruit bats to monoculture and polyculture farming in oil palm smallholdings. Acta Oecologica, 74, 11-18. https://doi.org/10.1016/j.actao.2016.06.005 
Turner, W., Spector, S., Gardiner, N., Fladeland, M., Sterling, E., \& Steininger, M. (2003). Remote sensing for biodiversity science and conservation. Trends in Ecology 83 Evolution, 18(6), 306-314. https://doi.org/10.1016/S0169-5347(03)00070-3

Vance, C. K., Tolleson, D. R., Kinoshita, K., Rodriguez, J., \& Foley, W. J. (2016). Near Infrared Spectroscopy in Wildlife and Biodiversity. Journal of Near Infrared Spectroscopy, 24(1), 1-25.

Voigt, C. C., Behr, O., Caspers, B., von Helversen, O., Knornschild, M., Mayer, F., \& Nagy, M. (2008). Songs, Scents, and Senses: Sexual Selection in the Greater Sac-Winged Bat, Saccopteryx bilineata. Journal of Mammalogy,89(6), 1401-1410. https://doi.org/10.1644/08-MAMM-S-060.1

Voigt, C. C., \& Kingston, T. (2016). Bats in the Anthropocene: Conservation of bats in a changing world. Springer Science+ Business Media.

Wong, S., Lau, S., Woo, P., \& Yuen, K. (2007). Bats as a continuing source of emerging infections in humans. REVIEWS IN MEDICAL VIROLOGY, 17(2), 67-91. https://doi.org/10.1002/rmv.520

Yoh, N., Syme, P., Rocha, R., Meyer, C. F. J., \& Lopez-Baucells, A. (2020). Echolocation of Central Amazonian 'whispering' phyllostomid bats: Call design and interspecific variation. Mammal Research, 65(3), 583-597. https://doi.org/10.1007/s13364-020-00503-0

Zhu, G., Chmura, A., \& Zhang, L. (2012). Morphology, Echolocation Calls and Diet of Scotophilus kuhlii (Chiroptera: Vespertilionidae) on Hainan Island, South China. Acta Chiropterologica, 14 (1), 175-181. https://doi.org/10.3161/150811012X654394

\section{Figure Legends}

FIgure 1: Sampling schedule and illustrations of bat sampling methods. Bat point counts were compared simultaneously against automated ultrasound recording and mist-netting in three oil palm plantation sites (Plots BP1, BP2, and BP3) for nine nights. Drawings by JABU studio.

Figure 2: Identification workflow of bat taxa sampled in oil palm plantations in Sumatra (Indonesia) with bat point counts, as well as traditional mist-netting and ultrasound recording methods. Bat point counts were used for a quarter of the sampling duration of the other methods. Call interval, start and end frequency were also used for the identification but are not shown here. Representative near-infrared photographs are shown; they belong to sequences of multiple pictures. Putative identification pathways are shown with a lighter gray tone. Asterisks denote near-infrared imagery that was not strictly needed for identification but that was used for identity confirmation. For mist-netting, numbers denote captures, and for bat point counts and ultrasound recordings, detections.

Figure 3: Rarefaction and extrapolation sampling curves for bat point counts, compared to established bat sampling methods. Shaded areas show $83 \%$ confidence intervals; differences in species richness are statistically significant when they do not overlap (Krzywinski \& Altman, 2013). Extrapolated values are only shown up to double the reference sampling size to avoid large prediction errors.

Figure 4 : Detection ranges and sampling locations for bat point counts, mist nets, and automated ultrasound recorders. The sampling rig and ultrasound recorder were set up at the sampling center. The thermal scope's field of view was scanning the thermal detection area. The curved ranges for ultrasound were drawn manually between the measured range directions. The ultrasound detection ranges are scaled to a maximum of $50 \mathrm{~m}$ as they are only representative of our $40 \mathrm{kHz}$ ultrasound emitter otherwise (SPL $48 \mathrm{~dB} @ 30 \mathrm{~cm}$ ). 


\section{Tables}

Box 1: Identification key for Sumatran bats occurring in oil palm plantations, based on categorical and relative morphological and acoustic features. The key is adapted to the current quality of near-infrared imagery obtained from bat point counts. The species list is based on our own checklist of bats sampled using mist nets in oil palm plantations (Darras, unpublished data). Fmax = frequency of maximal (i.e., peak) frequency.

1. We discriminate Pteropodidae from other bat families based on their morphological adaptation and behavior.

2. Pteropodidae have visibly enlarged eyes with a retroreflective layer (tapetum lucidum) to see in very low light levels (Muller et al., 2007; Ollivier et al., 2004). Their intrafemoral membrane and tail are inconspicuous, and they have a straighter flight compared to insectivorous bats that maneuver to hunt (pers. obs.). -2

3. Echolocating bats have characteristically small eyes, as they rely primarily on their auditory sense to navigate and forage. -5

4. We check the relative snout size using the head length (from back to snout tip) to head width (from throat to top) ratio:

5. Relatively short (ratio $<1.7$ ) and robust snout -3

6. Relatively long (ratio [?] 2) and narrow snout-4

7. We check for diagnostic features of different pteropodid genera:

8. Whitish digits (adult Cynopterus)

9. Spotted wings (Balionycteris maculata)

10. Black-capped head (Chironax)

11. None of the above (Megaerops/juvenile Cynopterus)

12. We check for the overall body size by comparison with photographed habitat features:

13. Very large (Pteropus)

14. Intermediate or small (Eonycteris/Rousettus/Macroglossus)

15. We distinguish echolocating families based on the relative size of the ears. Large ears are characteristic for bats passively listening for prey and are used to amplify the received ultrasound echoes (Obrist et al., 1993).

16. Ears approximately as large as the head, FM calls (Nycteridae, Megadermatidae) -6

17. Ears about half as large as the head or smaller -7

18. We use the tail to discriminate between both families:

19. Interfemoral membrane obvious, tail inconspicuous, Fmax $58 \mathrm{kHz}$ (Megaderma spasma)

20. Both interfemoral membrane and tail obvious, Fmax $97 \mathrm{kHz}$ (Nycteris tragata)

21. Further, we distinguish several families from their tail and interfemoral membrane shape:

22. Interfemoral membrane small, tail shorter than hind feet, ears half as large as head, nostrils open roughly perpendicularly to the open mouth, CF calls (Rhinolophus, Hipposideros) -8

23. Interfemoral membrane small but notable, tail inconspicuous (Coelops)

24. Obvious tail extending from the interfemoral membrane (Molossidae, Emballonuridae, Rhinopomatidae)

25. Tail enclosed in obvious interfemoral membrane, ears less than one third of the head, snout direction points in similar direction as the mouth (Vespertilionidae, Miniopteridae) -9

26. Several species can be distinguished from their calls' frequency of maximum energy:

27. Fmax $78 \mathrm{kHz}$ (Hipposideros orbiculus)

28. Fmax $137 \mathrm{kHz}$ (Hipposideros kunzi)

29. Fmax $65 \mathrm{kHz}$ (Rhinolophus sedulus)

30. Fmax $54 \mathrm{kHz}$ (Rhinolophus trifoliatus)

31. Vespertilionidae and Miniopteridae can be distinguished from the relative sizes of the phalanges of the third digit.

32. First phalange $<40 \%$ of second phalange (Miniopteridae) 
33. First phalange about as long as second phalange (Vespertilionidae)

Table 1: Comparison of practical aspects for the three bat sampling methods in our study, per sampling site and night, for comparable sampling effort and area.

\begin{tabular}{llll}
\hline Method & Point counts & $\begin{array}{l}\text { Mist netting (48 m 3 } \\
\mathrm{m})\end{array}$ & $\begin{array}{l}\text { Automated } \\
\text { ultrasound recording }\end{array}$ \\
\hline $\begin{array}{l}\text { Team size (persons) } \\
\begin{array}{l}\text { Equipment bulk } \\
\text { Price per site (EUR) }\end{array}\end{array}$ & $\begin{array}{l}\text { Moderate } \\
2200 \text { (current) to } 3000 \\
\text { (this study) }\end{array}$ & $\begin{array}{l}\text { High } \\
100 \text { to } 800 \text { (this study) }\end{array}$ & $\begin{array}{l}\text { Small } \\
120 \text { (current) to } 1200 \\
\text { (this study) }\end{array}$ \\
$\begin{array}{l}\text { Post-survey data } \\
\text { processing time } \\
\text { Expertise }\end{array}$ & None & High \\
$\begin{array}{l}\text { Metup effort } \\
\text { Migh (post-processing) }\end{array}$ & High & $\begin{array}{l}\text { Low (sampling) High } \\
\text { (post-processing) }\end{array}$ \\
& $\begin{array}{l}\text { Very high (initial } \\
\text { assembly) Low (per } \\
\text { survey) }\end{array}$ & High & Low \\
$\begin{array}{l}\text { Not possible when } \\
\text { shuttling between }\end{array}$ & $\begin{array}{l}\text { Possible to sample 2 } \\
\text { nearby sites } \\
\text { sith one team }\end{array}$ & $\begin{array}{l}\text { continuously with one } \\
\text { team }\end{array}$ & $\begin{array}{l}\text { Possible to sample } \\
\text { multiple sites } \\
\text { simultaneously with } \\
\text { several recorders }\end{array}$ \\
\hline
\end{tabular}

\section{Figures}
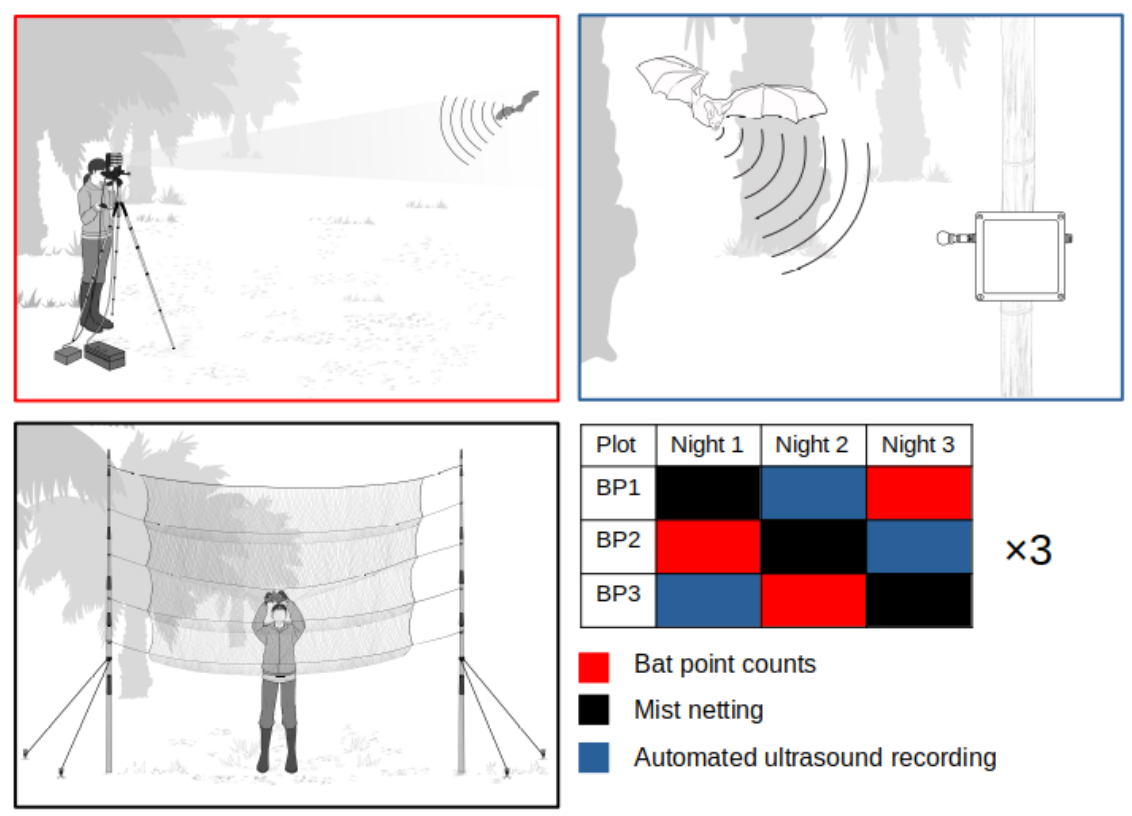

$\times 3$

Bat point counts

Mist netting

Automated ultrasound recording

FIgure 1 


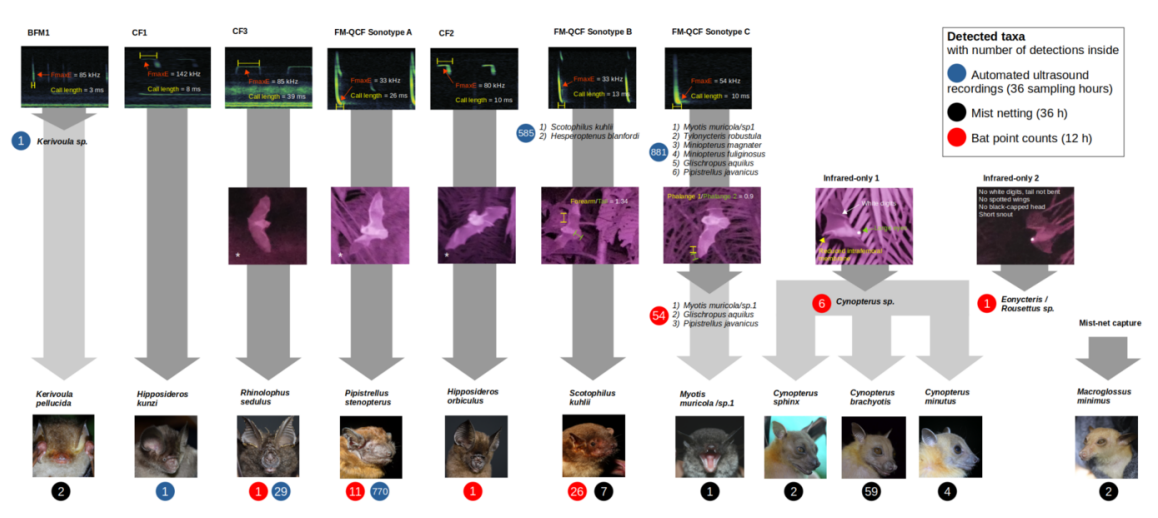

Figure 2
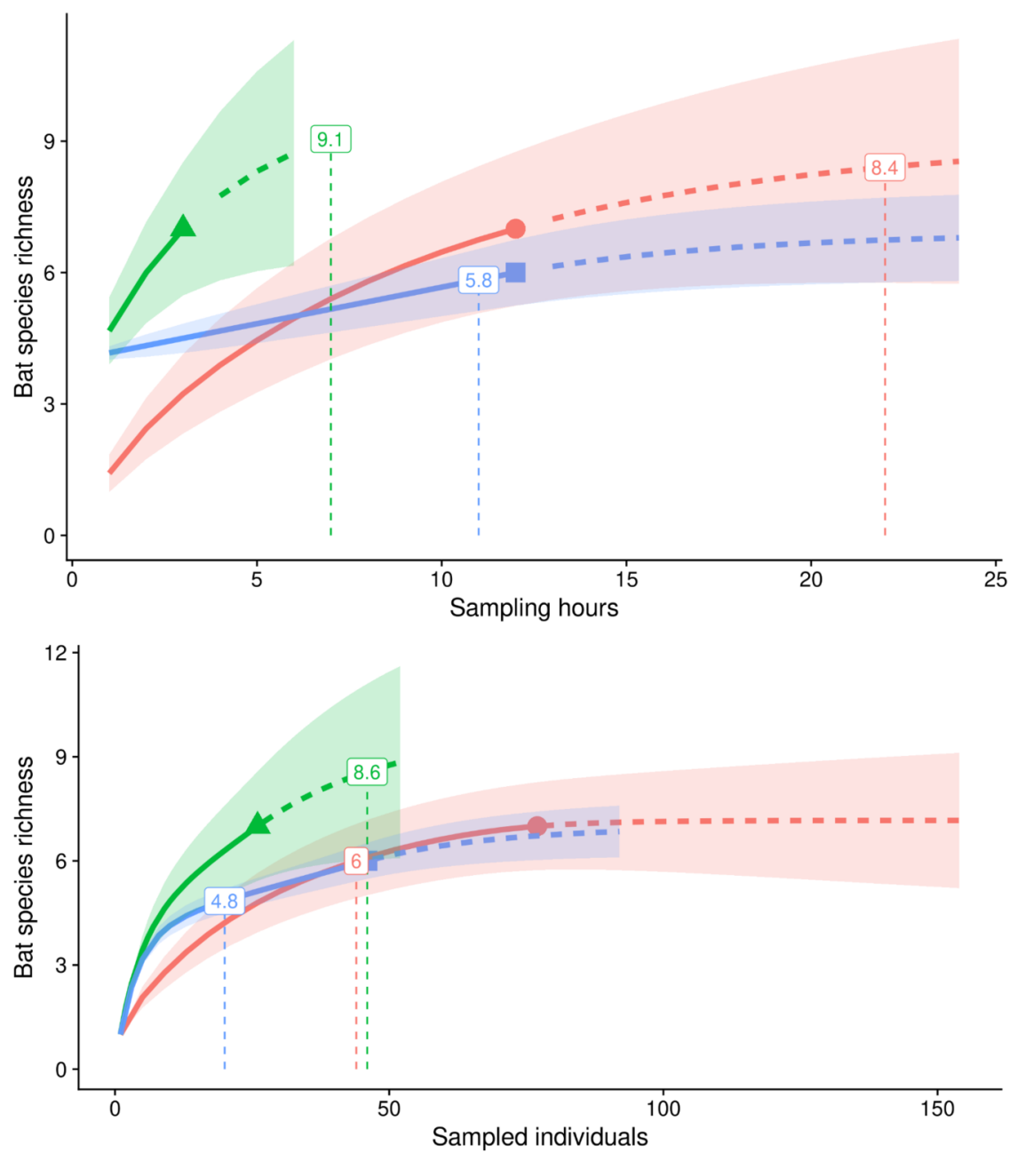

interpolated - - = extrapolated

$\square$ Mist-netting $\square$ Point count $\square$ Ultrasound recording 
FIgure 3

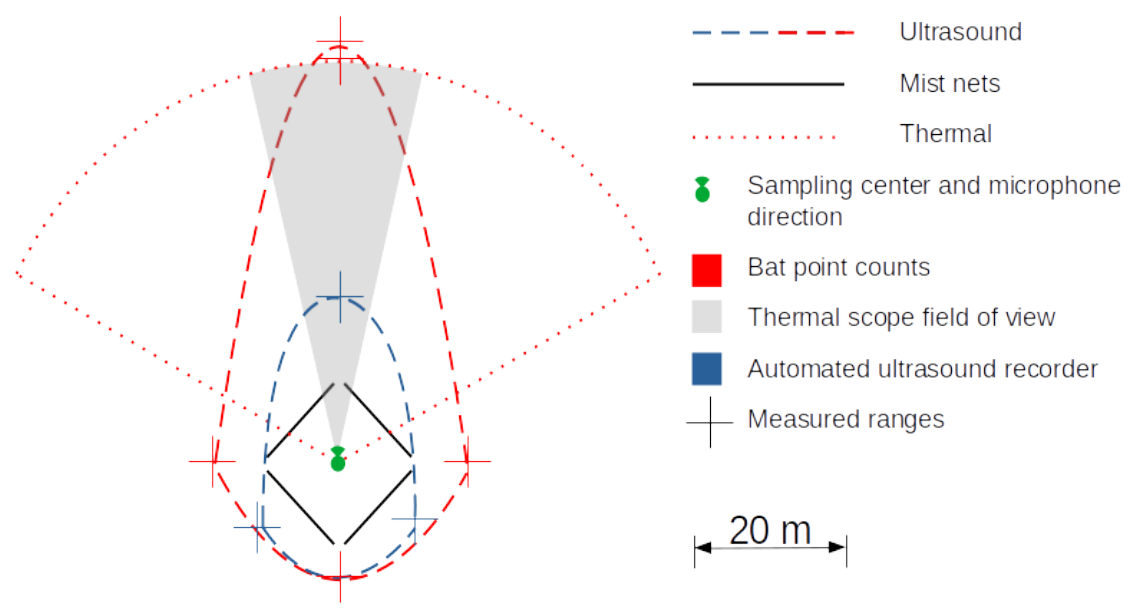

FIgure 4 